general practitioners we have never been approached by the Joint Formulary Committee for any criticisms or suggestions of the proposed layout of the Formulary. I have made similar suggestions to those given above in the past, but no notice has been taken.

It would be interesting to hear from othe doctors if they are totally satisfied with the layout of this essential book. Are the users, in contrast to the pharmaceutical and therapeutic interests, adequately represented on the Joint Formulary Committee ?-I am, etc.

London N.W.10. RoNALD LAw.

1 British National Formulary, 1968, British Medical Association ; Pharmaceutical Society of Grea

** The composition of the Joint Formulary Committee is given at p. 312 of the B.N.F., 1968.-ED., B.M.7.

\section{Road Traffic Accidents}

SIR,-There has recently been a postgraduate meeting in Hull on the topic of (road traffic) accident aftercare. The inference was made at this meeting that a rota could be made up of general practitioners in the East Riding area willing and able to make themselves available to dash to the scene of an accident and assist the ambulance, police, and fire services in the hope of preventing loss of life and unnecessary suffering to the victims of the accident.

Since our area is now well endowed with orthopaedic' surgeons who must surely be ideally suitable to cope with such accidents, and since most of these live well away from the centre of Hull and thus within easy reach of main roads carrying fast-moving traffic (that is, routes upon which serious accidents are most likely to occur), one must suggest that these gentlemen be approached first to form such a rota, rather than the general practitioner, who is likely to be less well equipped as regards availability and experience of such casualties.-I am, etc.,

\section{Cottingham}

\section{P. WHTTEHEAD.}

\section{Vaccination Certificates}

SIR,-Considerable inconvenience and much annoyance is often caused to travellers around the globe by incorrect or incomplete vaccination certificates.

In a recent check on smallpox vaccination certificates on a British passenger ship travelling around the world from the United Kingdom, of 913 passengers embarked 48 vaccination certificates had major omissions whicin required the owner to be revaccinated. From the western coast of North America of 616 passengers embarked 109 certificates were incorrect. Among the latter, the major error was an incorrectly written date (81), which was followed by omission of or incomplete batch numbers (22), and omission of the approved stamp (6). Canadian doctors can claim highest marks for clarity and correctness of certificates, while doctors from the U.S.A. and United Kingdom come lower on the list. Of the latter, those at fault seem to spread across the medical population from the Harley Street private practitioner through public health departments to the general practitioner.
It is therefore very worth while reminding doctors that from 1 January 1967 every smallpox vaccination certificate must show the origin and batch number of the vaccine used, the certificate should have an approved stamp, and the month of the year should be written in letters-that is, 1 December 1968 instead of 1.12.68. Port authorities do not appear to be so concerned regarding the last point, and it is therefore not considered a major error requiring the owner to be revaccinated.

Finally, it is amazing how many passengers will apparently judge their doctor by his capacity, or rather incapacity, to fill in what to the doctor is just yet another form.I am, etc.,

Oswestry, Salop.

S. F. L. LOWE.

\section{Mountain Accidents}

SIR,-Mr. N. F. Kirkman's letter on this subject (14 December, p. 703) has been brought to our notice. Accident report forms in use in Scotland are much more detailed than those used in England and Wales, and therefore much more information is available as to causes of accidents.

Mr. Kirkman gives "slips" as the major cause of accidents (109 out of 170). The reports available to us indicate that a slip is more an end result than a cause. In our 1967 list, out of nine slips on tourist paths in summer, six of those concerned were wearing smooth-soled shoes, hence the cause was unsuitable footgear. Similarly in winter, slips on snow slopes were found to be caused by lack of an ice axe, or inability to use an ice axe. Exposure also was found to be more often an end result than an original cause. The cause here varies : in some cases it is due to lack of map and compass, leading to the party concerned becoming lost in mist, and this wandering in turn leading to exhaustion and exposure. In other cases it is due to inadequate clothing.

Again Mr. Kirkman gives " bad weather" as a cause, but when full information is available it is usually found that the real cause is inability to deal with bad weather (common on our hills), resulting from inexperience or inadequate equipment. Curiously $\mathrm{Mr}$. Kirkman does not quote avalanches as a cause, though these are frequent on Scottish hills. Our 1967 list gives four avalanche accidents, in one of which one man was buried for nine hours and his companion for eleven hours.

Three years ago the International Federation of Mountaineers suggested that an accident report from all countries should be the same. This was not agreed to, but there is a strong case for the same type of form to be used throughout Britain. We feel that the form used in Scotland provides the essential information, and its use would provide much more information as to causes of accidents, leading in turn to much more being done for accident prevention.-We are, etc.,

\section{B. H. Humble.} Mountain Accident Recording, H. Macinnes. Honorary Secretary,
Mountain Rescue Committee, Scotland.

\section{Elderly in Hospital}

SIR,-I am grateful to Dr. A. M. Nussey (1 February, p. 313) for his comments on the paper by myself, Dr. K. W. Cross, and Miss Mary Wall (21 December, p. 763). But in face of the evidence of falling patient turnover in the region's geriatric beds he wonders whether it was a good plan to create a separate specialty of geriatrics. He should be reassured by the knowledge that there are geriatric units in the region where the turnover is double the regional average, and also where the turnover has been more than doubled during recent years. The creation of opportunities for the training of physicians in successful geriatric methods, including day hospitals, is the answer in a situation where an increase of only $50 \%$ in the present low rate of turnover would relieve the current state of bed block and abolish lists of patients awaiting transfer to geriatric units.

If geriatric turnover is suitably increased there will be no need for a great additional building programme, though replacement of outdated by modern accommodation will make it easier to obtain and retain devoted nurses, and there are areas where the proportion of beds in relation to the population to be cared for is much below average and new building is required.

The "reintegration of geriatrics into the mainstream of general medicine" that $\mathrm{Dr}$. Nussey suggests could be considered retrogressive, but, more important, it would fail to recognize that the mainstream in a few years will consist of patients over 65 in the sense that they will occupy more than half the hospital beds for adults, and the hospital service will have to be geared more closely to their special needs.-I am, etc.,

$$
\begin{gathered}
\text { Highcroft Hospital. } \\
\text { Birmingham 23. }
\end{gathered}
$$

\section{Status Epilepticus and Diazepam}

SIR,-I regret that some of your correspondents (15 February, pp. 439 and 440) should consider that the title of the paper "Dangers of Treatment of Status Epilepticus with Diazepam" is misleading. The title was not selected for notoriety nor to be dramatic, but to draw attention to dangers that must be considered. Hypotension and the attendant danger of cerebral vascular insufficiency in any patient suffering from a severe acute cerebral disorder is undesirable for reasons that should be obvious. Recognition of the potential danger may well prevent its appearance or lead to early and effective treatment.

Without doubt the full details of each individual case would have been desirable. More detailed information was submitted, but was not published because of the editorial consideration for space. Nevertheless, some of the information requested by Drs. D. C. Taylor and C. Ounsted is actually in the printed paper, shortened as it was, and other issues they raised are irrelevant. The difficulties of assessing the hypotensive effect of a drug in the clinical situation are indeed crucial, but should not have been unnecessarily complicated by their inference that cases of falls in blood pressure may have followed the intramuscular administration of 